\title{
A research agenda for English-medium instruction
}

\section{Conversations with scholars at the research fronts}

\author{
Pramod K. Sah \\ The University of British Columbia
}

\begin{abstract}
Since English-Medium Instruction (EMI) has emerged as an important field of policy and research, there are a multiplicity of issues that are unexamined but need critical attention. This paper features some key scholars of EMI who together highlight contemporary issues of EMI as a field of research and its primary future research agendas moving forward, including appropriate methods of collecting information about EMI. The nine researchers, who represent different geographical contexts (South/East Asia, Africa, Europe, and South America), have offered their views regarding the future research agendas of EMI. Based on the conversations with these researchers, this paper presents eight strands of EMI research agendas that need to be carried on.
\end{abstract}

Keywords: English-medium instruction, research agenda, the role of language, political economy, language assessment, professional development

\section{Introduction}

Over the last couple of decades, English-Medium Instruction (EMI) has emerged as a new field of study, motivating scholars from varied disciplines (e.g., applied linguistics, sociolinguistics, educational linguistics, linguistic anthropology) to understand its politics, pedagogy, and policy in both K-12 and tertiary education. EMI is currently one of the most prominent areas of research, primarily among applied linguists, which can be confirmed by many publications of edited volumes and special issues accounting for varied issues of EMI policies, discourses, and practices. The launch of the Journal of English-Medium Instruction is one key example, in addition to various universities offering graduate-level academic 
courses $^{1}$ and vocational training programs on EMI. However, since the field of EMI is relatively new, there are contradictions and, probably, confusion regarding the concept of EMI itself and its scope as a medium of instruction policy and a field of research. To this end, based on conversations with nine scholars of EMI, this paper aims to bring to the fore different strands of future EMI research, including some methodological issues.

I engaged in conversations with scholars representing different geographical contexts, such as South/East Asia, Africa, Europe, and South America, so we can understand EMI research practices from different parts of the world, and in order to include a broad range of researchers and their observations. The researchers who engaged in conversations are (listed alphabetically): Roger Barnard (Waikato University, New Zealand), M. Obaidul Hamid (University of Queensland, Australia), Anna Kristina Hultgren (The Open University, United Kingdom), Ernesto Macaro (University of Oxford, United Kingdom), Ron Martinez (University of California, Berkeley, United States), Lizzi O. Milligan (Bath University, United Kingdom), Heath Rose (University of Oxford, United Kingdom), Philip Shaw (Stockholm University, Sweden), and Yuen Yi Lo (University of Hong Kong).

\section{What should be on the EMI research agenda going forward?}

The key question that I asked all nine scholars was this: What do you think should be on the EMI research agenda going forward? What follows are their responses to this question, which, apart from having been edited for length, are reported largely verbatim. The interviews with M. Obaidul Hamid and Lizzi O. Milligan were in written exchanges, while the rest of them took place as conversations on Zoom.

\section{Interview 1: Roger Barnard}

EMI is greatly under-researched. My main interest is the nature of the medium of instruction. We talk about English-medium instruction, and, in quite a number of places, this means exclusively English. I can understand how this started because it happened that EMI began in Europe and mostly in northern European coun-

1. For example, the University of Bath offers an MA in English-Medium Instruction, the University of St. Andrews offers an M.Sc. in TESOL with specialization in English-Medium Instruction, and Dalhousie University offers a Certificate in English-Medium Instruction, to name a few. 
tries, where people have a high proficiency in English. Therefore, going to a British university or going to a Dutch University, or going to a German University and studying in English is not so problematic because both the students and the lecturers are themselves quite proficient in English. However, when it comes to EMI spreading across Asia, for example, the same situation is not true. With all due respect, neither many of the lecturers nor many of the students are competent to deliver and comprehend academic content exclusively in English. So, this raises the question of whether the medium of instruction should be entirely in English, mainly in English, or a blend of first and second languages. So, the research agenda should include empirical studies where observations are made, not judgmentally in any way, of how EMI lecturers and students use other languages, and for what purpose?

I realize that it is not always easy to get observational data. I think even notable experts find it difficult too. They may get formal access to EMI classes, but actual voluntary access is sometimes very difficult. So, it raises the question as to who would be best to observe such classes, whether directly in person or by video recordings.

\section{Interview 2: M. Obaidul Hamid}

Obviously, existing and ongoing research has covered many aspects of EMI including policy, processes, motivations, and stakeholder perceptions. Academic issues and challenges posed by EMI have received a lot of attention all the way through. Although EMI is not linked to any specific pedagogy, pedagogical issues including teaching and learning strategies are also drawing attention. Taxonomies and models of EMI have also been proposed. Although the all-time big question of the effectiveness of EMI [practices] has not attracted much research, this question is also being taken up, at least slowly.

I would like to add a few [items to the EMI] research agendas for the future. First, while a lot of research has been conducted on students' academic challenges including language issues, we would like to see what happens to those challenges over time. So, undertaking longitudinal research to follow the trajectory of EMI challenges for students will be important. Language Management Theory may provide a helpful theoretical lens for this research.

Secondly, we would like to see substantial research on the effectiveness of EMI at different levels of education. This research may require a comparison of different languages used as the medium of instruction. One strand of this research may also focus on what goes on in the classroom so we can identify appropriate EMI pedagogy and practices. 
Thirdly, it is noteworthy that researchers have started linking EMI to translanguaging ( $\mathrm{Sah} \& \mathrm{Li}, 202 \mathrm{O}$; Tsou \& Baker, 2021). While continuing this research, we may also want to draw on the world Englishes perspective to understand the nature of Englishes and genres that are produced by technologymediated EMI teaching and learning.

Finally, together with our interest in academic issues, we need to consider social and socio-cultural questions about EMI to understand how it may perpetuate the social divide (Jahan \& Hamid, 2019) as well as unite students of different language backgrounds in the same classroom and nurture a sense of community (Wijesekera \& Hamid, forthcoming).

\section{Interview 3: Anna Kristina Hultgren}

For me, what is most interesting is to actually use the phenomenon of EMI as a window into understanding wider societal issues; for instance, about social justice and equality, and how political processes come to shape language choice and language shift. For some time, there have been calls in sociolinguistics and applied linguistics to engage to a greater extent with the "political economy" (Block, 2017) because of the inequalities and complexities it generates. But how do we actually engage in such interdisciplinarity? What we are going to do in a recent UKRIfunded project (English as a Medium of Instruction in European Higher Education: Challenges and Opportunities for Europe and the UK) is try to bring together bodies of knowledge within political science and linguistics so that we can understand how political decisions and processes drive language shift, specifically EMI. We are living at a time when the world may be transitioning from one language to another, or at least to a wider range of semiotic and multilingual practices. So, it is a perfect moment in time to start to understand what actually drives language shift and associated multilingualism.

I also think there has been a lot of research on the attitudes of students and lecturers. But we know a lot less about the decision-makers, the people who are in power, and it is partly because they are more inaccessible. It requires linguists to engage with a completely different body of literature: we would need to engage with higher education studies, science studies, public administration, and academic governance; those bodies of literature, in order to understand the priorities of academic decision-makers and how EMI features (or not) in that. I think we need to reach out to them both at the institutional level, to university decision-makers, and also at the national level, to ministers of education, and at the supranational level [bureaucrats in the supranational organizations]. 


\section{Interview 4: Ernesto Macaro}

I think in terms of identifying what EMI is, it would be good if research made a comparison between various disciplines. I think in the past, I have talked about what I call "hardcore EMI disciplines," such as science and engineering and mathematics, and slightly "softer EMI" was where you cannot avoid using English or very difficult to avoid using any such as business studies and TESOL. I would distinguish between those two. But, again, I think comparisons between those different disciplines would be very useful.

What research lacks to establish is whether EMI improves English language learning. I think there is some evidence that it does, but does it do it better than TEFL? And how have the designs been appropriate in those studies, which have shown some advantages for EMI? The big question then is to what extent content learning suffers as a result of being taught through the medium of the second language (i.e., English), as opposed to through the home language of the students or at least the majority of the students and so forth.

I have recently been gaining interest in what the students are doing in the EMI context. I think that they have been neglected to some extent. They have been asked a lot of questions about how they feel about EMI, but we have not actually asked what challenges they face and how they deal with those challenges. We need to start asking them what they actually do in order to improve themselves and their learning. Similarly, I suppose, in the end, we have to take one step further, and say, what kind of professional development programs [for teachers] are most effective to bring about changes.

Further, we need to continue asking the big questions about the impact on societies and individuals. There is evidence that EMI is creating or exacerbating educational and social elitism, and that is a problem. It may not be totally avoidable, but we need to think about what the best models are.

Lastly, there is a question of who owns EMI, meaning who are the people doing the research into EMI? If you look at, for example, who are the people that are publishing in EMI, they are almost all applied linguists, and they are publishing mostly in applied linguistics journals or ones which are slight hybrids but really are former applied linguistics journals. Very few authors are collaborating with the subject specialists in the research in that field.

\section{Interview 5: Ron Martinez}

There is already extensive research geographically in Europe, Western Europe, especially, and I feel that is a context that we know something about but there are other many areas of the world that I feel we still need to know more about. I 
obviously represent one of those areas, which is Brazil, South America. I wonder to what extent research findings from one context apply to these other cultures, other realities, and it is my feeling that there are going to be a lot of things that we have in common, but there are a lot of other newer issues that arise. For example, unlike institutions in Europe, the highest research-intensive universities in Brazil are absolutely free because all the money comes from the government. There is not a kind of profit motive involved in the teaching of EMI. It is not like they want to attract people from other countries so that they can boost their enrollments or anything like that. Their motivations for EMI are different.

The key research agenda can be in terms of English itself, the "E" in EMI. Even though a lot has already been discussed what English we should [follow], and what models we should follow. People have danced around the question of proficiency a little bit and I have addressed that question to some extent in my own research, which is, to what extent does proficiency in English affect one's ability to teach through English? I feel that until we address that kind of elephant in the room, it leaves a door open for people to say, "Well, I do not have enough English to teach through English." We need to be able to show those people who are at B2 proficiency level, for example, that the research shows that there are a lot of instructors [with low proficiency] who students judge as being very effective, and they do not need to have this very high level of proficiency and, therefore, be more inclusive.

Another research agenda can be in terms of language use in EMI classrooms. In Brazil, there will be a Brazilian lecturer teaching through English to a cohort of Brazilians, who have the shared first language. So, everybody is doing a kind of similar EMI wherein they all speak the same language, but they choose to do it through English for a number of reasons. Those reasons should be explored more through research. Because you have a shared language other than English in a classroom, an instructional environment also means that people can easily move in and out of Brazil, Portuguese and English. So, a useful role for languages other than English, or how languages other than English are used is also a very interesting research agenda moving forward.

\section{Interview 6: Lizzi O. Milligan}

In my mind, the majority of the current EMI research agenda focuses on higher education and the technicalities within the classroom (e.g., English language gains in EMI contexts). Going forward, I would hope that we will see much more attention being paid to the millions of children who are forced to learn in English from as early as the first year of primary school, as is the case in Cameroon, for example. There is so much more we need to know about how learning in English 
impacts on these children's language identity, epistemic access to the curriculum and literacy/language development in any language. Existing research suggests that certain groups of learners are significantly disadvantaged by this (those who live in the poorest countries/regions/communities/families, for example) but I think we should be doing more to understand how EMI contributes to, and deepens, existing inequalities (cf. Milligan, 2020). As researchers, I think, we need to not only understand these issues but also advocate for changes in language of instruction policies to better support those most disadvantaged.

I hope that as the field of EMI grows, the research agenda will also become more theoretically informed and theoretically expansive. By that, I mean that I hope for an agenda that brings together scholars of linguistics, political science, history, cultural studies and education to explore the many ways that EMI impacts learners and helps to maintain the broader socio-economic status quo (at global, national and local levels). This is the most exciting aspect of the future agenda, for me, and I hope that this new journal will be a space for such dialogue and theory building to happen.

\section{Interview 7: Heath Rose}

I think that a lot of the drive for EMI at the moment is through top-down policymaking because there are certain widely held beliefs by stakeholders, who are not necessarily reading the research, that believe that EMI will bring the university and their students' certain benefits. There are beliefs that EMI might lead to greater job prospects, opportunities to study abroad, increased rankings of the institution, increased opportunities for student mobility, and miraculous improvement in student's language proficiency through introducing EMI. There is also a belief that their [students'] content learning will not be affected by this [change in medium of instruction]. So, I think one area of research is really needed is to investigate thoroughly whether EMI actually brings the purported benefits that a lot of policymakers believe.

The other area that really needs investigation is the potential disadvantages of EMI for education and for society. Actually, this ties in a lot with your research in the context of Nepal (e.g., Sah \& Karki, 2020; Sah \& Li, 2018). There is also research that has come from contexts like China and other places recently that really points to the fact that, in many educational contexts, EMI is positioned as education for the elite. If English becomes an extra barrier for students to access elite forms of education, then we have a problem. I think that this issue [of access to education] has not been fully explored yet and needs to be unpacked in future research. So, those two areas of research dovetail together, indicating that we need real investigation into what the perceived benefits of EMI are, and empirically show 
these perceived benefits as real outcomes; and what the disadvantages of EMI are. And we need to empirically show evidence of these disadvantages because I think without that empirical base, we do not have a language to communicate with stakeholders about what needs to change in the future.

\section{Interview 8: Philip Shaw}

One thing that I think should be on the agenda is attention to the tendency for EMI to spread downwards in the school system, so there are even primary schools and secondary schools offering EMI. I think that issues about language maintenance and effective literacy have become more important, the lower down we go. If we look at, for example, the death of Gaelic in Scotland, the children in schools stopped speaking Gaelic in the playground and started speaking English. I do not know whether there is any tendency for that to happen in English-medium schools in Scandinavia, for example, where fluency is quite high. But in [places] where proficiency is high, I can imagine that the classroom language can leak out into the playground language, and then there is actually language shift. My own ideological position is that I do not think language shift is a very good idea. So, I think there should be studies of what is going on in schools, especially among younger pupils, and especially the impact on L1 proficiency.

Another thing I would very much like to see is a much more detailed study of what is going on in the classroom. In Swedish universities, you typically have a group of Chinese students sitting in a corner; one of them is whispering to the others all the time because one of them understands the lecture in English and they are cooperative. So, that person translates the lectures for the others. Meanwhile, some of the lecturers might say that they need to mix with others and practice English. Hence, this phenomenon needs to be unpacked.

For another agenda, there are issues associated with native speakerism of English, as some teachers are not counted as a native speaker because they have the wrong kind of accent. So, I would like to know how far those kinds of attitudes exist and how they can be combatted. I can imagine that in East Asia, that is quite a big issue because I know that in Japan, for example, teachers have got to look like a native speaker.

\section{Interview 9: Yuen Yi Lo}

I think there are three directions for future EMI research agendas. The first one would be teachers' pedagogical practice. Especially in Hong Kong, the previous research has shown that students may suffer in their content knowledge in academic achievement in EMI schools. So, we cannot just use English as the medium 
of instruction, and not provide language support to the students. Language may not be one of the goals, but it sometimes is actually the goal, which may be more implicit. If there is an implicit goal, we really need to provide more scaffolding, more teaching in that sense. So that is the pedagogical part and the issue is how teachers can really integrate more language teaching or language scaffolding in the EMI lessons. I think that is important but, so far, it is very difficult because content subject teachers are trained as content specialists.

The second part, much related to the first part, is the professional development of EMI teachers. If we are advocating some pedagogical practices for more effective EMI teaching, then we need to provide professional development or like teacher education for EMI teachers. Then, the question is how we can do that. I think we need more research in this area. We also need to think about teacher collaboration. If they can collaborate with their language specialists in the schools, then the kind of professional development would be more sustainable because external support like university consultants or teacher educators is temporary.

The third one is the assessment of EMI students or bilingual education students. In EMI contexts where most of the students are language majority students and they speak the language of the society, I think the question of the validity of assessment has not been widely discussed or researched. That is why I have been doing research in this area of assessment in EMI to see what that is and whether the EMI students are disadvantaged because of the language barrier, especially when their content knowledge is assessed through the second/additional language.

Conclusion: Key issues and research strands

Based on the conversation with all the scholars, I have summarized eight strands of EMI research that need attention as the field moves forward (see Figure 1). Each of these EMI research strands can have a multiplicity of research questions, overlapping with some of the questions listed in Macaro et al. (2018), that we can develop and address through different research designs.

First, focusing within the strand of the nature of the medium of instruction, we can ask questions in relation to (a) the ways teachers/lecturers and students use other languages than English and the functions/purposes that serve, (b) the scope of translanguaging/multilingualism in EMI, (c) problematizing the "E" as well as the "I" in EMI, not only from a multilingual but also from World Englishes or ELF (English as a lingua franca) perspectives, (d) the discourse of native-speakerism in EMI programs, and (e) the relationship between one's proficiency in English and ability to teach EMI courses. 


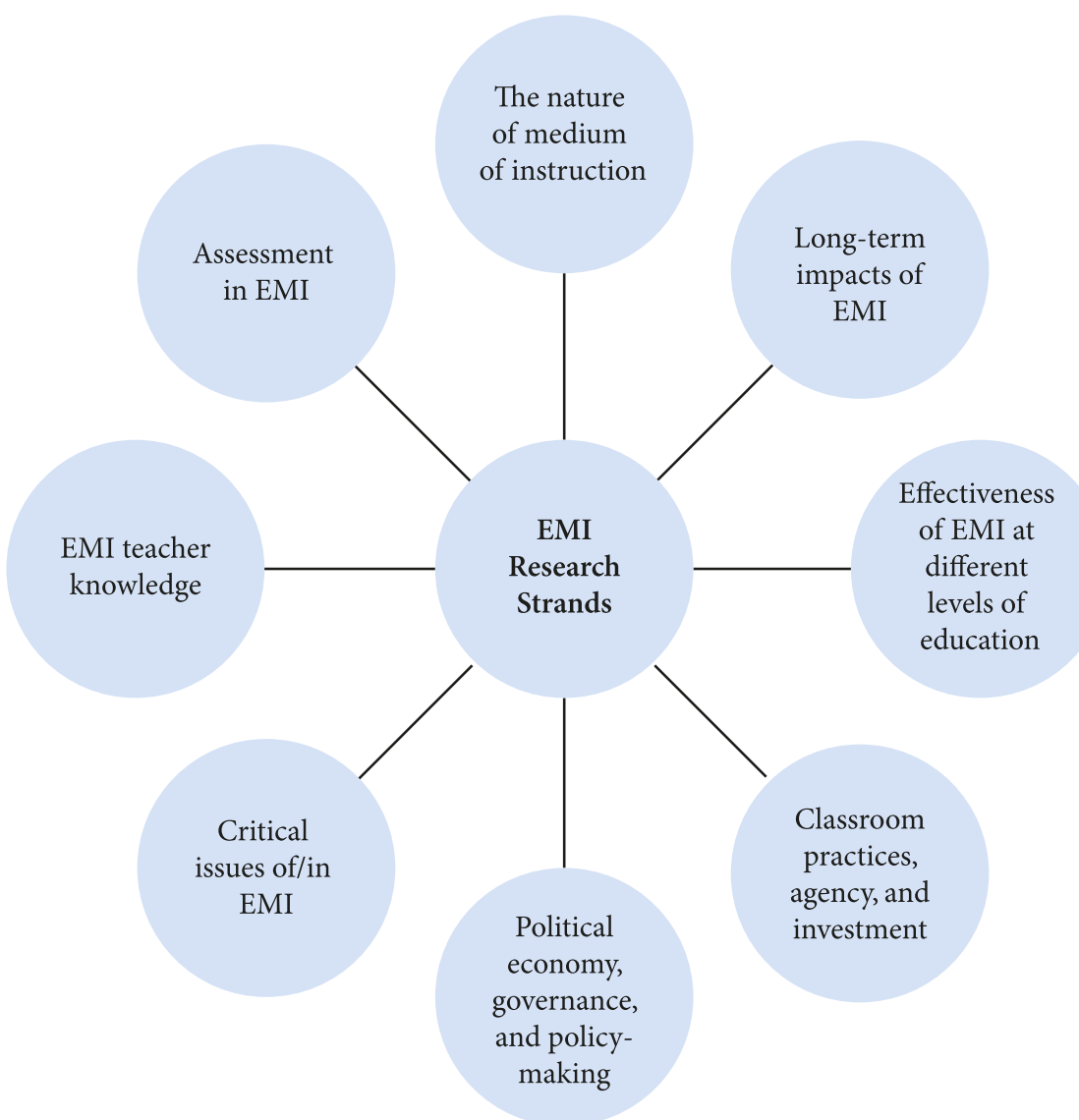

Figure 1. EMI research strands

The second strand of long-term impacts on learning, access, emotions, identity, and equity can include research questions in terms of (a) what happens to academic and emotional challenges that both teachers and students face over time and (b) the experience of transitioning to EMI higher deduction from either EMI or non-EMI school education. We need to also investigate the long-term impact of EMI on L1 proficiency, attitudes toward L1 and other local languages, and language maintenance at both institutional and societal levels. Similarly, to investigate the effectiveness of EMI at different levels of education, we can investigate (a) whether EMI improves English language learning and if it does better than teaching English as an additional language, (b) the extent to which content-learning suffers as a result of EMI, as opposed to the use of students' home languages or the mixture of different languages, and (c) whether the promised benefits of EMI which different stakeholders buy into - are actually attained. There is also a strong 
consensus among the scholars that future research should dig into classroom practices, agency, and investment to document what students actually do (and with what agency and investment) to improve and negotiate their learning. There is meager knowledge on the agency of both teachers and students and their creation of discourses and counter-discourses of the EMI policy in the classroom.

Another set of important questions should be in terms of political economy, governance, and policymaking. As Kristina Hultgren has pointed out, the key question that we should be asking is how political decisions made at different levels (e.g., international, national, institutional, individual) come to shape the choice of language(s) as the medium of instruction as well as the language shift. Given the fact that education has become a service industry in the capitalist world (Olssen \& Peters, 2005), we need to examine political-economic discourses associated with the EMI policy in both school and higher education, also unpacking the ways such discourses (re)produce inequalities. It is meanwhile crucial to understand the alignments/misalignments in the perspectives, ideologies, and agencies of different policy actors. And, if EMI is desirable and the only option, future research should pave a way for bottom-up policymaking processes, which are locally responsive. These issues also connect to a need for scrutinizing critical issues in/of EMI, which have unfortunately received very little attention, mainly within the higher education context. Future EMI research should ask how EMI perpetuates the social division, in addition to observing its impacts on local language ecology and diverse students' identity, emotions, and epistemic access to the curriculum.

Teacher knowledge is another under-researched area of EMI research, although there are frequent reminders of teachers struggling in EMI programs pedagogically and linguistically. Our research should document not only the preparedness and reflectiveness of teachers to deliver EMI lessons but also create foundations for professional development programs and models. Similar to investigating students' personas in EMI, it is equally important to research, for example, the emotions, anxiety, and identity negotiation and (re)construction of teachers. Equally important is to seek through our research the possibilities and efficacy of teacher collaboration - language teachers and content-area teachers working together in EMI programs. The last strand of research needing critical attention is in terms of assessment. We need to be examining what modes of assessment are utilized to evaluate bi/multilingual students' learning and what components, either or both English language and content knowledge, are prioritized. 


\section{References}

Block, D. (2017). Political economy in applied linguistics research. Language Teaching, 5o(1), 32-64. https://doi.org/10.1017/So261444816000288

Jahan, I., \& Hamid, M.O. (2019). English as a medium of instruction and the discursive construction of elite identity. Journal of Sociolinguistics, 23, 386-408. https://doi.org/10.1111/josl.12360

Macaro, E., Curle, S., Pun, J., An, J., \& Dearden, J. (2018). A systematic review of English medium instruction in higher education. Language Teaching, 51(1), 36-76. https://doi.org/10.1017/S0261444817000350

Milligan, L.O. (2020). Towards a social and epistemic justice approach for exploring the injustices of English as a medium of instruction in basic education. Educational Review. https://doi.org/10.1080/00131911.2020.1819204

Olssen, M., \& Peters, M.A. (2005). Neoliberalism, higher education and the knowledge economy: From the free market to knowledge capitalism. Journal of Education Policy, 2o(3), 313-345. https://doi.org/10.1080/02680930500108718

Sah, P.K., \& Karki, J. (2020). Elite appropriation of English as a medium of instruction policy and epistemic inequalities in Himalayan schools. Journal of Multilingual and Multicultural Development. https://doi.org/10.1080/01434632.2020.1789154

Sah, P. K., \& Li, G. (2018). English medium instruction (EMI) as linguistic capital in Nepal: Promises and realities. International Multilingual Research Journal, 12(2), 109-123. https://doi.org/10.1080/19313152.2017.1401448

Sah, P. K., \& Li, G. (2020). Translanguaging or unequal languaging? Unfolding the plurilingual discourse of English medium instruction policy in Nepal's public schools. International Journal of Bilingual Education and Bilingualism. https://doi.org/10.1080/13670050.2020.1849011

Tsou, W., \& Baker, W. (Eds.). (2021). English-medium instruction translanguaging practices in Asia: Theories, frameworks and implementation in higher education. Springer.

Wijesekera, H.D., \& Hamid, M. O. (forthcoming). The dynamics of bilingual education in post-conflict Sri Lanka. In L. Adinolfi, U. Bhattacharya, \& P. Phyak (Eds.), Multilingual education in South Asia: At the intersection of policy and practice. Routledge.

\section{सार (Nepali abstract)}

अंग्रेजी माध्यम शिक्षाको मुद्दा अनुसन्धान र निति निर्माण गर्नुपर्ने एक महत्वपूर्ण विषयको रुपमा देखापरेता पनि यस विषयमा धेरै मुद्दाहरू बारे अध्ययन भइसकेको छैन तर ती मुद्दाहरूमाथि ध्यान दिनु अपरिहार्य छ। यस लेखमा अंग्रेजी माध्यम शिक्षामा दखल राख्नेकेही विद्वानहरूले यसको अनुसन्धानबारे समसामयिक मुद्दाहरू, उपयुक्त तथ्याङ्क संकलन विधिहरू लगायत भावी अनुसन्धानका मुख्य एजेण्डाबारे छलफल गरेका छन्। भावी अनुसन्धानका एजेण्डाबारे विभिन्न भौगोलिक क्षेत्र जस्तै दक्षिण पूर्वी एशिया, अफ्रिका, युरोप र दक्षिण अमेरिकाको प्रतिनिधित्व गर्दे नौ जना अनुसन्धानकर्ताले आफ्नो विचार र अनुभव प्रस्तुत गरेका छन् । ती अध्येतासँगको कुराकानीको आधारमा यस लेखले अंग्रेजी माध्यम शिक्षा सम्बन्धि अनुसन्धानका आठ क्षेत्रहरु प्रस्तुत गरेको छ। 
Address for correspondence

Pramod K. Sah

The University of British Columbia

5525 Presidents Row

Vancouver, BC, V6T $1 \mathrm{~L}_{5}$

Canada

pramodtesol@gmail.com

\section{Publication history}

Date received: 4 October 2021

Date accepted: 28 October 2021 